\title{
Article \\ Experimental Study on the Effect of Gas Volume Fraction on the Cavitation Performance of a Low-Specific-Speed Centrifugal Pump
}

\author{
Linglin Jiang, Houlin Liu, Yong Wang *, Yanhong Mao, Runze Zhou and Jianbin Gu
}

Citation: Jiang, L.; Liu, H.; Wang, Y.; Mao, Y.; Zhou, R.; Gu, J.

Experimental Study on the Effect of Gas Volume Fraction on the

Cavitation Performance of

a Low-Specific-Speed Centrifugal

Pump. Water 2022, 14, 798. https://

doi.org/10.3390/w14050798

Academic Editor: Giuseppe Pezzinga

Received: 8 February 2022

Accepted: 28 February 2022

Published: 3 March 2022

Publisher's Note: MDPI stays neutral with regard to jurisdictional claims in published maps and institutional affiliations.

Copyright: (c) 2022 by the authors. Licensee MDPI, Basel, Switzerland. This article is an open access article distributed under the terms and conditions of the Creative Commons Attribution (CC BY) license (https:// creativecommons.org/licenses/by/ $4.0 /)$.
Research Center of Fluid Machinery Engineering and Technology, Jiangsu University, Zhenjiang 212013, China; j112566465@163.com (L.J.); liuhoulin@ujs.edu.cn (H.L.); maoyanhong33@163.com (Y.M.); zhourunze945@gmail.com (R.Z.); unn9714@gmail.com (J.G.)

* Correspondence: wylq@ujs.edu.cn

\begin{abstract}
In order to study the cavitation performance of centrifugal pumps with low specific speeds under the condition of gas-liquid two-phase flow, a cavitation test rig for pumping gas-liquid two-phase flow was set up. The cavitation performance of the pump with a specific speed of 32 was studied. The variation of the head, pressure pulsation intensity, and vibration intensity with the cavitation allowance $\mathrm{NPSH}_{\mathrm{a}}$ (Net Positive Suction Head available) of the centrifugal pump were obtained at different inlet gas volume fraction (IGVF) conditions of $0,1 \%, 2 \%$, and $3 \%$. The results show that the cavitation performance of a low-specific-speed centrifugal pump can be improved obviously in a certain liquid flow range when the IGVF is $1 \%$, especially at a low liquid flow rate. When cavitation did not occur or the degree of cavitation was low, a lower IGVF can reduce pressure pulsation intensity at the pump outlet and the vibration intensity at the pump inlet under design flow rate and high flow rate conditions. Additionally, all performances of the low-specific-speed pump are more sensitive to gas when the liquid flow rate is low. The results can provide a reference for improving the cavitation performance of low-specific-speed pumps for transporting gas-liquid two-phase flow and single-phase liquids.
\end{abstract}

Keywords: centrifugal pump with low specific speed; gas-liquid two-phase flow; cavitation; cavitation performance; experiment research

\section{Introduction}

When local pressure in the liquid system is lower than the liquid saturated vapor pressure at the current temperature, the liquid in this region will change phase to form bubbles and grow rapidly. This process is called cavitation [1]. Cavitation will not only lead to an obvious decline in hydraulic machinery performance, the damage of material surface, and an increase in vibration and noise, but also cause damage to the inlet and outlet pipelines of the pump, thus restricting the development of hydraulic machinery $[2,3]$.

A centrifugal pump is common hydraulic machinery. Low-specific-speed centrifugal pumps $\left(10<n_{\mathrm{S}}<80\right)$ are widely used in aerospace, the petrochemical industry, the metallurgical industry, and other fields because of their low flow rate and high head [4]. However, passages between the impeller blades of low-specific-speed centrifugal pumps are long and narrow. Once cavitation occurs, bubbles will soon fill passages; thus, the head and efficiency of the pump will decline sharply, which affects the safe and stable operation of the pump [5]. With the rapid development of aerospace technology, the petrochemical industry, and the metallurgical industry, the medium that needs to be transported is diversified increasingly. Meanwhile, the media conveyed by low-specific-speed centrifugal pumps have also expanded from single-phase liquids to gas-liquid two-phase flows and from non-vaporized media to gradually vaporized media [6]. In the above-mentioned industries with very high safety requirements, it is necessary to ensure the smooth operation of the 
pump assembly [7]. Therefore, it is of great significance to study the influence of inlet gas characteristics on the cavitation characteristics of low-specific-speed centrifugal pumps to ensure their safe and stable operation $[8,9]$.

A lot of numerical calculation studies and experimental studies have been carried out on the cavitation performances of centrifugal pumps [10,11]. Georgios et al. studied the inception and development of cavitation in three different impellers using visual experiments and monitored the changes of the head, vibration, and noise. It was found that the $\mathrm{AE}$ sensors and acceleration sensors can identify cavitation long before the total head drop operating point, and the lower incidence angle and the use of splitter blades can reduce cavitation noise and vibration characteristics [12]. Wang Y. et al. experimentally studied the effects of the blade number on cavitation-induced vibration and the noise of centrifugal pumps. It was found that the vibration of the pump with five blades was the relative minimum, and with the aggravation of cavitation, the shaft frequency peak of the noise signal of the model pump showed a downward trend [13]. Duplaa et al. studied how the unsteady phenomenon of cavitation occurred during the rapid starting process of a centrifugal pump using an experiment. The pressure pulsation at the tongue, inlet, and outlet of the pump was measured, and the evolution process of cavitation initiation and development was also recorded with a high-speed camera. It has been shown that low final flow rates usually generate low cavitating conditions at the end of the startup, whereas increasing the final flow rate results in more developed cavitating conditions, leading to progressive head drop in the pump [14]. Coutier-Delgosha et al. studied cavitation types and cavitation distribution in cylindrical vane centrifugal pumps with different geometric parameters through experiments and numerical simulations. It was found that the main features of the cavitating flow field are correctly simulated by the improved calculation model [15]. Mousmoulis G. et al. studied the influence of tip clearance and tip thickness on the cavitation performance of a centrifugal pump equipped with a semiopen impeller through numerical simulations, which was verified through visualization experiments. It was found that the flow pattern at the blade's tip clearance region includes important secondary flows that recirculate part of the tip flow back to the suction side of the blade and back to the inlet of the impeller, and both these recirculating flows disturb the main flow field in the impeller and create conditions that favor cavitation creation and development [16]. Wang Y. et al. proposed a two-phase, three-component cavitation model suitable for the numerical calculation of cavitation flow in a centrifugal pump. Compared with the experimental results, it was found that this model could predict the external characteristics and cavitation distribution of the centrifugal pump better [17]. Wang, J et al. proposed the RZGB cavitation model according to the rotating characteristics of the centrifugal pump, which could predict the cavitation structure and the cavitation evolution process more accurately. Meanwhile, the image preprocessing method based on gray standard deviation was proposed, which can evaluate the area with cavitation risk in the centrifugal pump better [18].

Many numerical calculation studies and experimental studies have also been carried out on the gas-liquid two-phase flow performances of centrifugal pumps $[19,20]$. Sato S. et al. experimentally studied the performances of the centrifugal impeller with variable blade outlet angles under both single- and two-phase flow conditions. It was found that the performances of the movable bladed impeller are improved by installing diffuser vanes in air-water two-phase flow conditions at relatively small water rates; however, the improvement by installing of diffuser vanes disappears at high water flow rates [21]. Yuan S. et al. used the SUMIG model to accurately predict the gas-liquid two-phase performance of a centrifugal pump. It was found that when the gas content is less than $3 \%$, the internal flow is relatively stable; however, when the gas content is $5 \%$, gas accumulation occurs and the performance of the pump drops suddenly [22]. Yuan J. et al. studied the flow characteristics of centrifugal pumps when transporting the gas-liquid mixture based on the Eulerian-Eulerian inhomogeneous model. It was found that gas concentration is high at the inlet pressure side of the blade, where the vortex exists, indicating that the gas concen- 
tration has a great relationship with the vortex aggregation in the impeller passages [23]. Neumann M. et al. experimentally studied the gas distribution in a centrifugal pump under different gas volume fractions, and quantitatively studied the gas phase distribution in the impeller area of the centrifugal pump using HIRE CT and time-averaged rotating synchronous CT scanning. It was found that the installation position has only a minor effect on the pump performance in comparison to the inlet flow conditions. In addition, for the first time, thin gas films at the pressure side of the impeller wheel blades could be visualized in an industrial centrifugal pump [24]. Shao C. et al. conducted a visualization experiment with a high-speed camera to study the gas-liquid two-phase flow pattern inside the centrifugal pump, and four flow patterns of separation bubble flow, bubble flow, balloon flow, and gas-liquid separation flow were obtained [25]. Ge Z. et al. established the gas-liquid two-phase coupling calculation model based on the CFD-PBM simulation method, and verified this with experiments. It was found that when the gas volume fraction reached a certain value, the bubbles that accumulated in the impeller were more than those in the volute [26]. Si Q. et al. carried out the numerical calculation of a centrifugal pump by using Euler-Euler heterogeneous flow model to analyze the performance of a centrifugal pump under different gas volume fractions. The head of the pump dropped obviously under the condition of low flow rate, and the gas was more concentrated near the pressure surface of the blade inlet, gathering serious vortexes [27].

Although studies on cavitation and gas-liquid two-phase flow of centrifugal pumps have achieved fruitful results, the research on the cavitation of centrifugal pumps under the condition of gas-liquid two-phase flow has hardly been carried out. In this paper, a centrifugal pump with specific speed of 32 is taken as the research object, and the cavitation performance of the centrifugal pump is studied through experiments under different IGVF conditions, which can provide a reference for the improvement of cavitation performance of low-specific-speed centrifugal pumps for transporting gas-liquid two-phase and single-phase liquids.

\section{Test Measuring System}

\subsection{Testing Apparatus}

The research object in this paper is a centrifugal pump with a specific speed of 32, which is directly driven by a three-phase asynchronous motor. Additionally, the pump is designed for the experiment. The sketch of the pump is shown in Figure 1. The main parameters of the pump and motor are shown in Table 1.

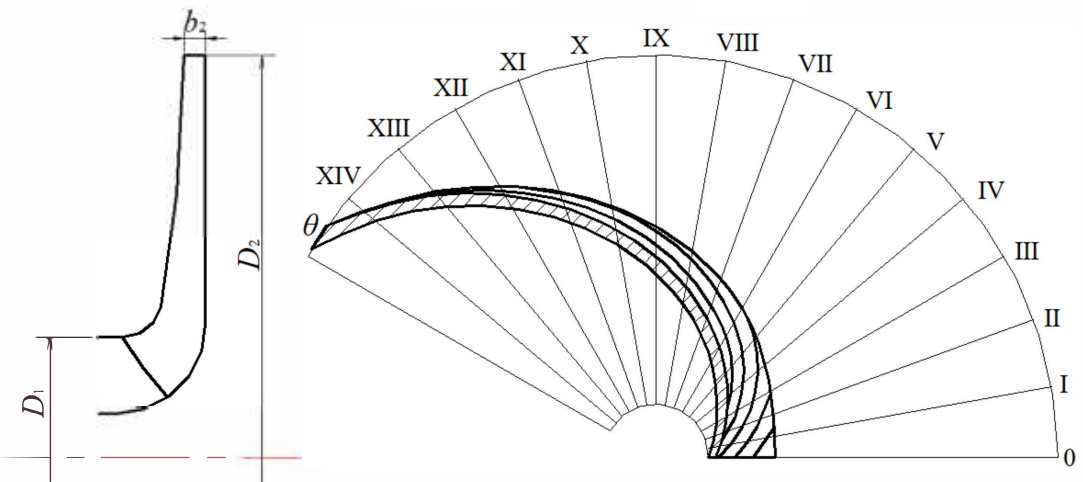

(a) Impeller

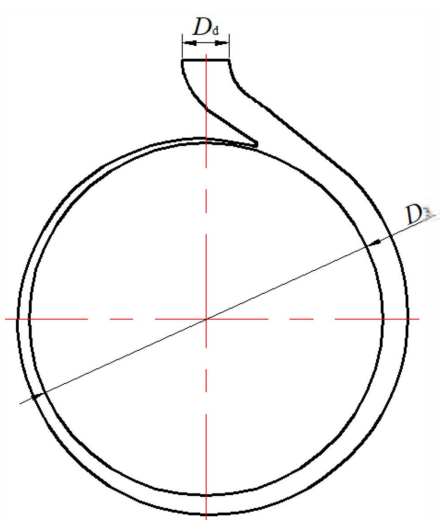

(b) Volute

Figure 1. Schematic diagram of the test rig. 
Table 1. Main parameters of the model pump.

\begin{tabular}{ccc}
\hline Parameter & Description & Value $/ \mathbf{m m}$ \\
\hline$D_{\mathrm{j}}$ & Inlet diameter of the pump $/ \mathrm{mm}$ & 50 \\
$D_{1}$ & Inlet diameter of the impeller $/ \mathrm{mm}$ & 68 \\
$D_{2}$ & Outlet diameter of the impeller $/ \mathrm{mm}$ & 228 \\
$b_{2}$ & Outlet width of the impeller $/ \mathrm{mm}$ & 6 \\
$D_{3}$ & Base diameter of the volute $/ \mathrm{mm}$ & 245 \\
$D_{\mathrm{d}}$ & Outlet diameter of the pump $/ \mathrm{mm}$ & 32 \\
$\theta$ & Blade wrap angle ${ }^{\circ}$ & 145 \\
$Z$ & Blade number & 6 \\
$n_{\mathrm{d}}$ & Rated speed of the pump $/\left(\mathrm{r} \cdot \mathrm{min}^{-1}\right)$ & 2950 \\
$Q_{l d}$ & Rated flow of the pump $/\left(\mathrm{m}^{3} \cdot \mathrm{h}^{-1}\right)$ & 20 \\
$H$ & Rated head of the pump $/ \mathrm{m}$ & 74 \\
$P$ & Motor power $/ \mathrm{kW}$ & 11 \\
\hline
\end{tabular}

Experiments were carried out in the laboratory of the National Pump and System Engineering Technology Research Center, Jiangsu University. The structure of the test rig, presented in Figure 2, is composed of a gas and a liquid circulation line. The whole test system consists of the following four parts: a pipeline circulation system (water tank, exhaust tank, inlet pipe, outlet pipe, return pipe, inlet valve, and outlet valve), a gas intake system (air compressor, buffer tank, pressure reducing valve, air inlet line, and air control valve), a test section (model pump and motor), and a data acquisition system (external characteristic acquisition system, dynamic pressure acquisition system, and vibration acquisition system). The test site is shown in Figure 3.

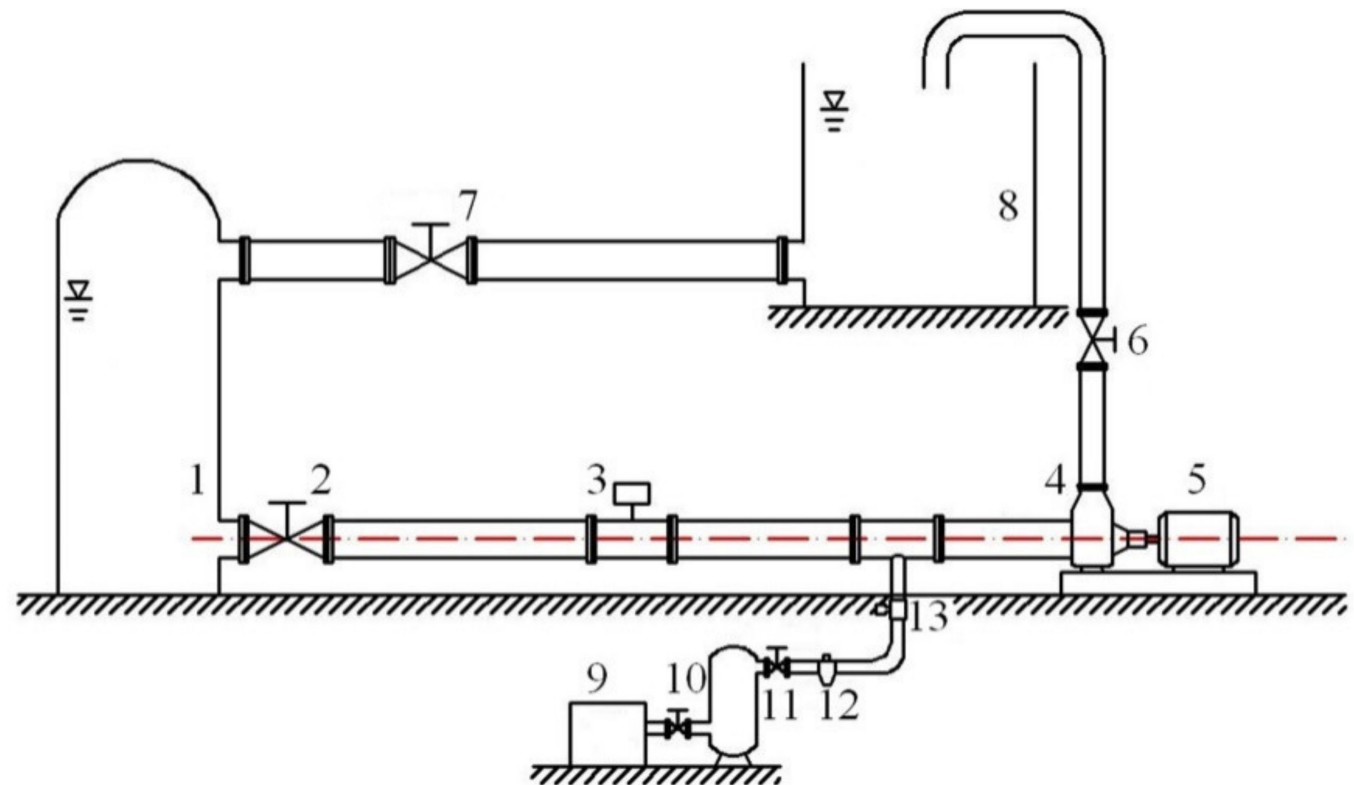

Figure 2. Schematic diagram of the test rig: 1. water tank, 2. inlet valve, 3. electromagnetic flowmeter, 4. model pump, 5. motor, 6. outlet valve1, 7. outlet valve2, 8. exhaust tank, 9. air compressor, 10. buffer tank, 11. air control valve, 12. pressure-reducing valve, 13. rotameter. 


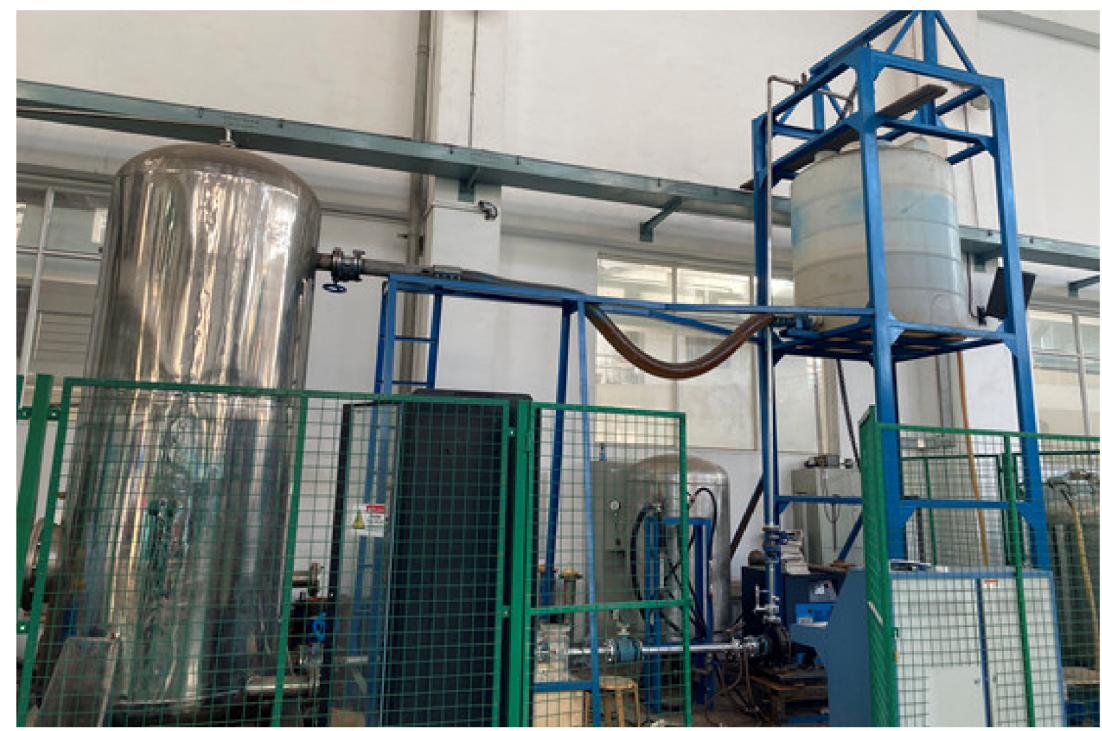

Figure 3. Test site.

\subsection{Data Acquisition System}

External characteristic data of the model pump were collected using a self-developed data acquisition system, and the data were processed using self-developed analysis software. The inlet pressure, outlet pressure, liquid flow rate, rotational speed of the model pump, voltage, current, and power of the motor were acquired using the data acquisition system. An MIK-P300 pressure transmitter was adopted as the inlet pressure sensor and outlet pressure sensor, whose range is $0- \pm 100 \mathrm{kPa}$ and $0-1 \mathrm{MPa}$, respectively, and the accuracy for both is $\pm 0.5 \%$. A KEFN-DN50 electromagnetic flowmeter with a range of 1-30 $\mathrm{m}^{3} / \mathrm{h}$ and an accuracy of $\pm 0.5 \%$ was adopted as the liquid flowmeter. A high-speed Hall sensor with a range of $0-5000 \mathrm{r} / \mathrm{min}$ and an accuracy of $\pm 0.2 \% \mathrm{FS}$ was adopted for measuring rotational speed. An LZ-W30-10 glass rotameter was adopted as the gas flowmeter, and the accuracy of the flowmeter is $\pm 0.25 \% \mathrm{FS}$ and the range of the flowmeter is $0.1-1 \mathrm{~m}^{3} / \mathrm{h}$ and $0.25-2.5 \mathrm{~m}^{3} / \mathrm{h}$, which can meet the gas flow rate range of $0.1-3.5 \mathrm{~m}^{3} / \mathrm{h}$.

The pressure pulsation data and vibration data of the pump were acquired using the INV3020 series high-performance 24-bit sampling instrument of the Oriental Institute of Vibration and Noise Technology, and the data were processed using the supporting Coinv DASP 10 software. An HY6305 liquid level transmitter with a range of $0-1 \mathrm{MPa}$ and an accuracy of $\pm 0.25 \%$ FS was adopted as the outlet pressure pulsation sensor of the model pump. INV9822 piezoelectric uniaxial acceleration sensors with a range of $0.5-8 \mathrm{kHz}$ were adopted as the vibration sensors. Two pressure sensors and one pressure pulsation sensor were installed on the pipeline and three acceleration sensors were installed at the pump inlet, pump outlet, and pump foot, respectively, as shown in Figure 4. In the experiment, the sampling frequency of $10.24 \mathrm{kHz}$ and the sampling time of $10 \mathrm{~s}$ were set in the DASP acquisition system.

In order to judge accuracy of the external characteristic data of the test rig, an analysis of the experimental uncertainty of the measurement system is needed. Generally speaking, the uncertainty analysis of a fluid machinery test rig is the error analysis of efficiency measurement, including systematic error and random error. Therefore, the uncertainty of the system in this paper is $0.68 \%$. 


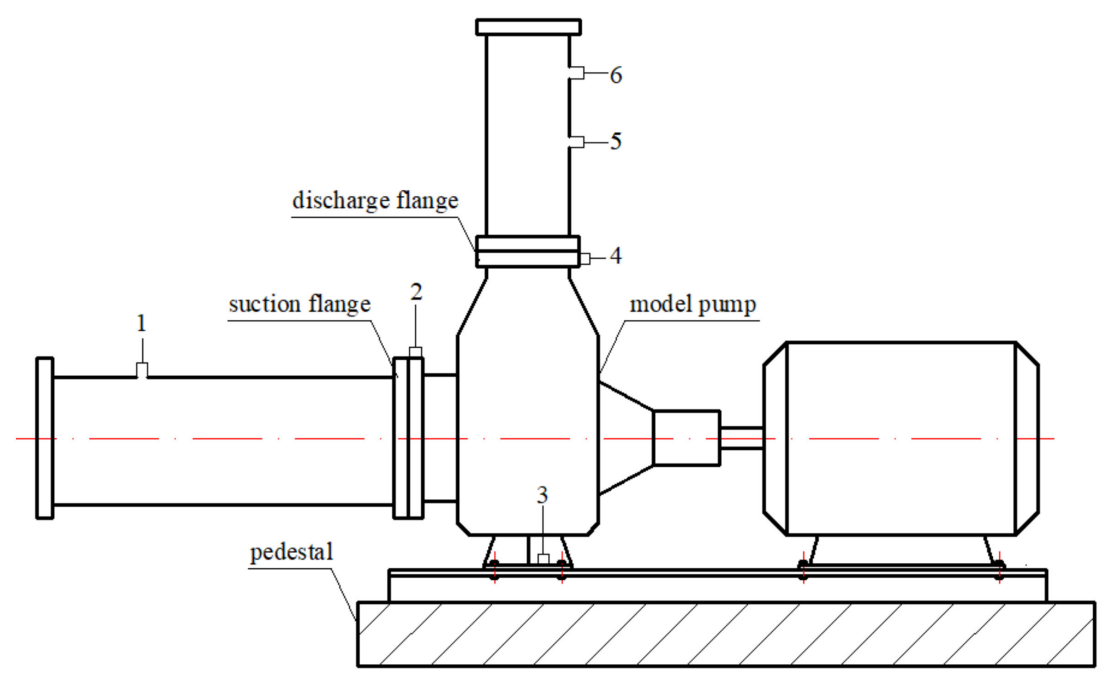

Figure 4. Installation position of sensors: 1 . inlet pressure sensor, 2. acceleration sensor at pump inlet, 3. acceleration sensor at pump foot, 4 . acceleration sensor at pump outlet, 5 . outlet pressure pulsation sensor, 6 . inlet pressure sensor.

\subsection{Experimental Process}

In order to facilitate the description of the inlet gas content, the IGVF is introduced. The definition of the IGVF is shown in Equation (1), which can be calculated using the inlet gas volume flow rate $Q_{g}$ and the inlet liquid volume flow rate $Q_{l}$.

$$
\mathrm{IGVF}=\frac{Q_{g}}{Q_{g}+Q_{l}} \times 100 \%
$$

In order to study the effect of the IGVF on the cavitation performance of the model pump, cavitation performance tests under gas-liquid two-phase conditions were carried out. The test process was as follows:

(1) The pump started to run when the inlet valve was fully opened and the outlet valve1 was closed. The outlet valve1 was opened gradually after the pump had started running, and the outlet valve1 was adjusted to ensure that the liquid volume flow rate was rated as flow $1.0 Q_{l d}$ after the rotational speed of the pump reached the rated speed $n_{d}$.

(2) During the test, the inlet valve was closed gradually to slowly reduce the inlet pressure of the pump, that is, to reduce the cavitation allowance $\mathrm{NPSH}_{\mathrm{a}}$ of the device. At the same time, the outlet valve1 was adjusted to ensure that the liquid volume flow rate remained at $1.0 Q_{l d}$. After the pump had operated stably under the above conditions every time, the test data should be recorded and, at this point, the cavitation performance of the model pump under the condition of $1.0 Q_{l d}$ is acquired when the IGVF is 0 .

(3) Then, the gas intake system was opened and the pressure-reducing valve was adjusted to control the gas volume flow rate on the basis of the above operation. At this point, the cavitation performance values of the model pump under the condition of $1.0 Q_{l d}$ at different inlet gas content conditions (IGVF $=1 \%, \mathrm{IGVF}=2 \%, \mathrm{IGVF}=3 \%$ ) were acquired.

(4) All the above operations were repeated to acquire the cavitation performance of the model pump under the condition of $0.75 Q_{l d}$ and $1.25 Q_{l d}$, respectively, when the inlet gas content was IGVF $=1 \%$, IGVF $=2 \%$, and IGVF $=3 \%$.

\section{Results and Discussion}

\subsection{Cavitation Characteristic}

The head of the model pump changes with the cavitation allowance $N P S H_{a}$ of the device under different liquid flow rate conditions and different IGVF conditions, as shown in Figure 5. 


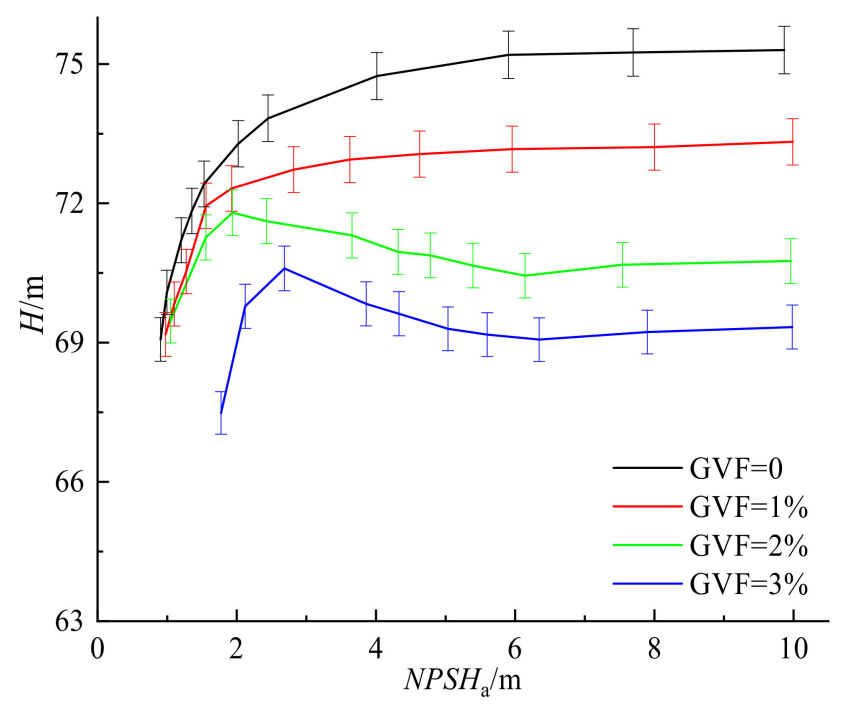

(a)

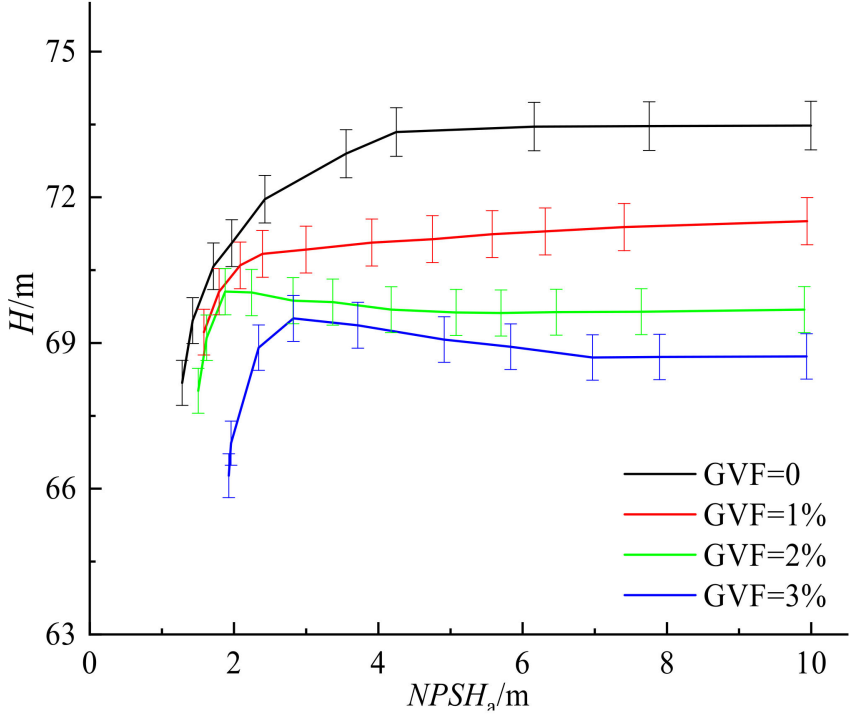

(b)

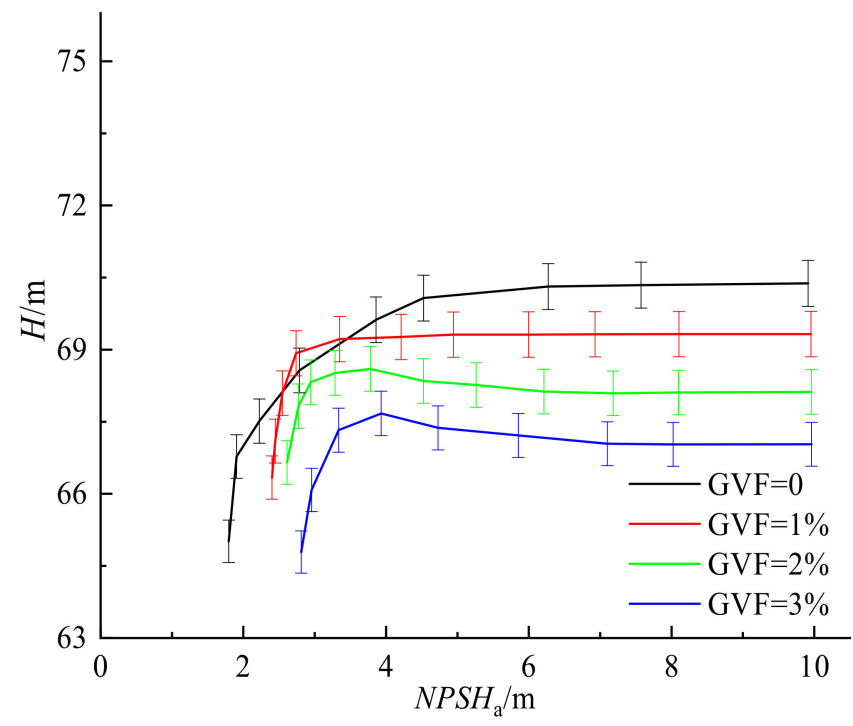

(c)

Figure 5. Cavitation performance of the model pump under different IGVF conditions and different flow rates: (a) $0.75 Q_{l d}$ (b) $1.0 Q_{l d}$ and (c) $1.25 Q_{l d}$.

Comparing the maps obtained for the three different mass flow conditions, reported in Figure 5, it can be clearly seen that for all the tested values, the higher the IGVF is, the lower the head of the model pump is. At the same time, when $N P S H_{\mathrm{a}}$ is large, the head of the model pump almost does not change. With constantly decreasing $N P S H_{\mathrm{a}}$ values, the head of the model pump changes significantly. After $N P S H_{\mathrm{a}}$ decreases to a certain point, the head of the model pump begins to drop sharply.

In the process of constantly decreasing $N P S H_{a}$, the head of the model pump varies significantly under different IGVF conditions, but there are obvious differences in the variation rules. Under different liquid flow rate conditions, when the IGVF is $1 \%$, the head of the model pump changes in basically the same way as the condition of IGVF $=0$, which decreases with the decrease in $\mathrm{NPSH}_{\mathrm{a}}$. When the IGVF is $2 \%$ and $3 \%$, the head increases gradually first and then decreases rapidly with the decrease in $N P S H_{\mathrm{a}}$ after $N P S H_{\mathrm{a}}$ becomes lower than a certain value.

On the basis of different types of cavitation characteristic curves of centrifugal pumps, the common standard of critical cavitation margin $N P S H_{\text {cri }}$ was determined. Under the 
cavitation performance curves corresponding to IGVF $=0$ and IGVF $=1 \%$, the $N P S H_{\mathrm{a}}$ is equal to the $\mathrm{NPSH}_{\text {cri }}$ when the head is decreased by $3 \%$. Under the cavitation performance curves corresponding to IGVF $=2 \%$ and $\mathrm{IGVF}=3 \%$, the $N P S H_{\mathrm{a}}$ corresponding to the intersection point of horizontal section and inclined section of the cavitation characteristic curve is the NPSHcri.

The critical cavitation allowance $N P S H_{\text {cri }}$ of the model pump under different liquid flow rate conditions and different IGVF conditions is shown in Table 2. It can be clearly seen from Table 2 that when the IGVF is $0, N P S H_{\text {cri }}$ increases with the increase in the liquid flow rate, and $N P S H_{\text {cri }}$ is increased from $1.88 \mathrm{~m}$ at $0.75 Q_{l d}$ to $2.62 \mathrm{~m}$ at $1.25 Q_{l d}$; that is, the cavitation performance of the model pump declines with the increase in the liquid flow rate. Compared with the condition of IGVF $=0$, the cavitation performance of the model pump is improved at $0.75 Q_{l d}, 1.0 Q_{l d}$, and $1.25 Q_{l d}$ when the IGVF is $1 \%$, and the improvement is more significant at a low liquid flow rate. The $N P S H_{\text {cri }}$ is decreased from $1.88 \mathrm{~m}$ with the IGVF $=0$ to $1.38 \mathrm{~m}$ with the IGVF $=1 \%$ under $0.75 Q_{l d}$, which a decreased of $26.6 \%$. The $N P S H_{\text {cri }}$ is decreased from $2.62 \mathrm{~m}$ with the IGVF $=0$ to $2.47 \mathrm{~m}$ with the IGVF $=1 \%$ under $1.25 Q_{l d}$, which is only a decrease of $5.73 \%$. The reason for the above phenomenon is that a small amount of gas occupies the low pressure area near the blade inlet edge of the low-specific-speed centrifugal pump, making the occurrence of the cavitation lag. When the IGVF is $2 \%$, the cavitation performance of the model pump is still improved at $0.75 Q_{l d}$ and $1.0 Q_{l d}$, but the cavitation performance declined at $1.25 Q_{l d}$. When the IGVF is $3 \%$, the cavitation performance of the model pump decreases at $0.75 Q_{l d}, 1.0 Q_{l d}$, and $1.25 Q_{l d}$ and the decrease is more significant at a high liquid flow rate. The $N P S H_{\text {cri }}$ is increased from $2.62 \mathrm{~m}$ with the IGVF $=0$ to $3.30 \mathrm{~m}$ with the IGVF $=3 \%$ under $1.25 Q_{l d}$, which is an increase of $25.6 \%$. The NPSHcri is increased from $1.88 \mathrm{~m}$ with the IGVF $=0$ to $2.09 \mathrm{~m}$ with the IGVF $=3 \%$ at $0.75 Q_{l d}$, which is only an increase of $11.2 \%$. This is because as the IGVF increases, the flow disorder in the low-specific-speed centrifugal pump increases, which increases the impact loss and makes the cavitation occur in the pump in advance.

Table 2. $N P S H_{\text {cri }}$ of the model pump under different conditions.

\begin{tabular}{|c|c|c|}
\hline$Q_{l}$ & IGVF/\% & $\mathrm{NPSH}_{\mathrm{cri}} / \mathrm{m}$ \\
\hline \multirow{4}{*}{$0.75 Q_{l d}$} & 0 & 1.88 \\
\hline & 1 & 1.38 \\
\hline & 2 & 1.40 \\
\hline & 3 & 2.09 \\
\hline \multirow{4}{*}{$1.0 Q_{l d}$} & 0 & 2.20 \\
\hline & 1 & 1.62 \\
\hline & 2 & 1.79 \\
\hline & 3 & 2.46 \\
\hline \multirow{4}{*}{$1.25 Q_{l d}$} & 0 & 2.62 \\
\hline & 1 & 2.47 \\
\hline & 2 & 2.88 \\
\hline & 3 & 3.30 \\
\hline
\end{tabular}

\subsection{Pressure Fluctuation Characteristic}

In order to facilitate the comparison of the pressure pulsation at the outlet of the model pump under different conditions, the pressure pulsation coefficient $C_{p}$ is introduced, and its definition is shown in Equation (2).

$$
C_{p}=\frac{p-\bar{p}}{0.5 \rho u_{2}^{2}}
$$

where $p$ is the instantaneous pressure at the pump outlet $(\mathrm{Pa}), \bar{p}$ is the average pressure obtained by calculating the arithmetic mean of the instantaneous pressure at the pump 
outlet $(\mathrm{Pa}), \rho$ is mean density of the medium $\left(\mathrm{kg} / \mathrm{m}^{3}\right)$, and $\mathrm{u}_{2}$ is circumferential velocity at the impeller outlet $(\mathrm{m} / \mathrm{s})$.

In order to analyze the characteristic of pressure pulsation intensity at the outlet of the model pump under different cavitation degrees and different IGVF conditions more clearly, the pressure pulsation coefficient root-mean-squared value $C$ is introduced, and its definition is shown in Equation (3).

$$
C=\sqrt{\frac{1}{N}} \sum_{k=1}^{N} C_{p k}^{2}
$$

where $C_{p k}$ is the pressure pulsation coefficient at different moments, $k=1,2,3,4, \ldots, N$.

The pressure pulsation coefficient root-mean-squared value $C$ at the model pump outlet changes with the cavitation allowance $N P S H_{\mathrm{a}}$ of the device under different liquid flow rate conditions and different IGVF conditions, as shown in Figure 6.

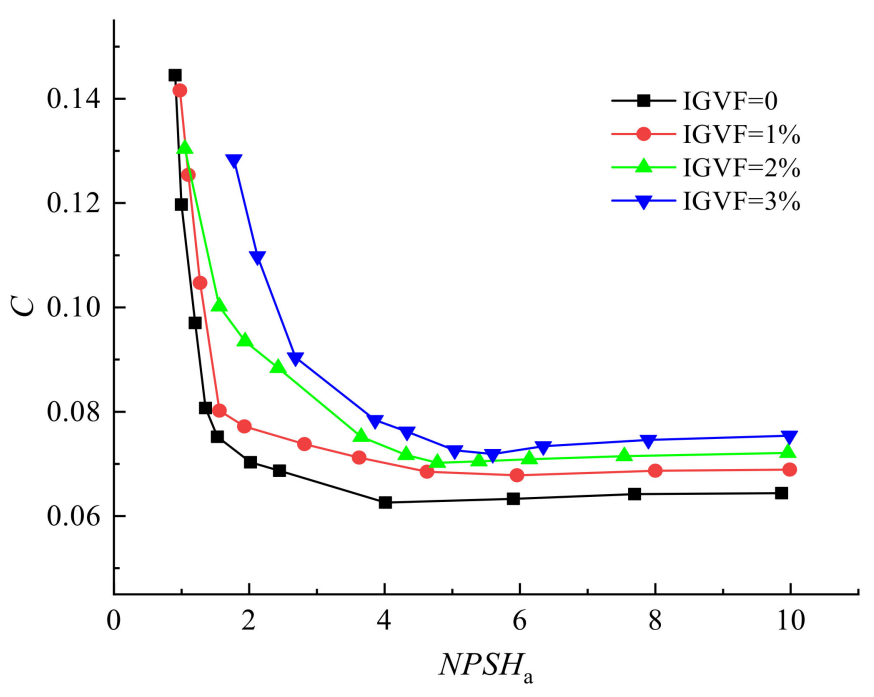

(a)

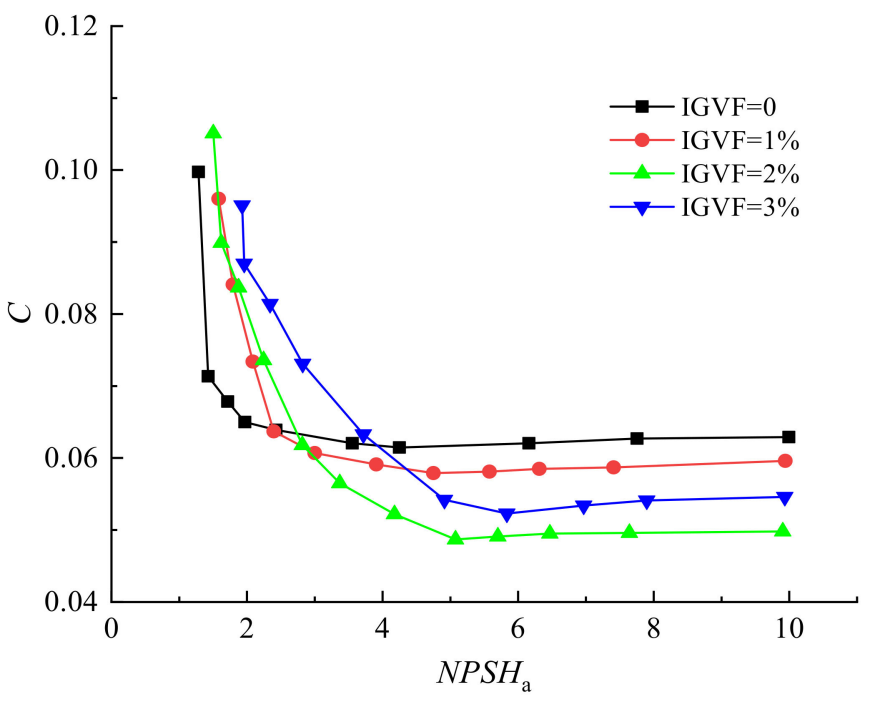

(b)

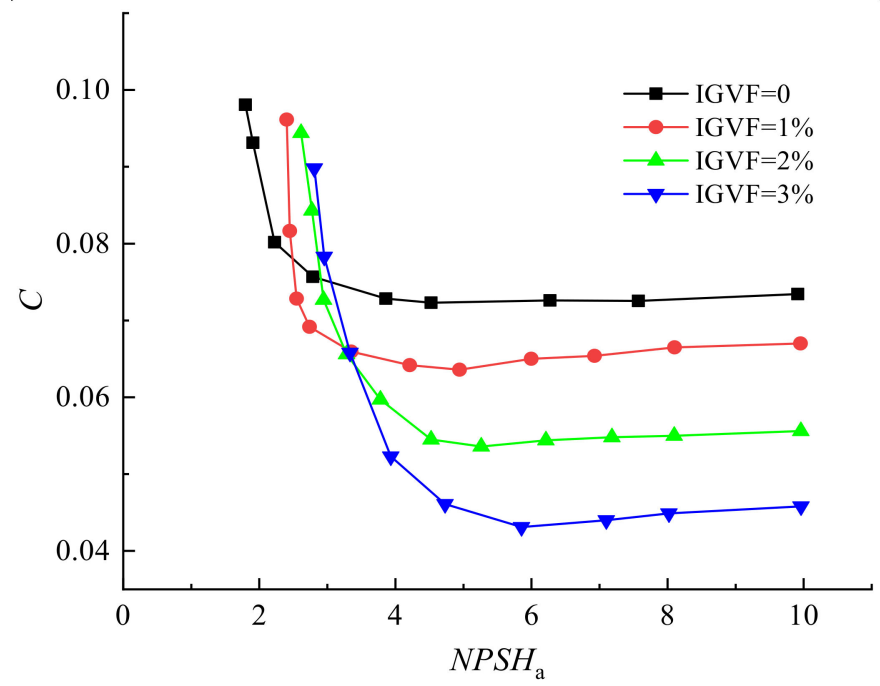

(c)

Figure 6. Pressure pulsation intensity of the model pump under different IGVF conditions and different flow rates: (a) $0.75 Q_{l d}$ (b) $1.0 Q_{l d}$ and (c) $1.25 Q_{l d}$.

Comparing the maps obtained for the three different mass flow conditions, reported in Figure 6, it can be clearly seen that for all the tested values, the pressure pulsation intensity 
changes slightly first and then increases significantly with the decrease in NPSH$H_{\mathrm{a}}$. This is because with the decrease in $\mathrm{NPSH}_{\mathrm{a}}$, the cavitation degree of the model pump is increased and the bubble generated from the cavitation is increased. As the pressure rises from the inlet to the outlet of the model pump, the influence of the bubble collapse on the pressure pulsation at the model pump outlet also increases.

It can also be seen from Figure 6 that the pressure pulsation intensity at the model pump outlet is increased slightly with the increase in the IGVF when $N P S H_{\mathrm{a}}$ is large at $0.75 Q_{l d}$, and the pressure pulsation intensity is increased from 0.064 with the IGVF $=0$ to 0.074 with the IGVF $=3 \%$. The pressure pulsation intensity at the model pump outlet is decreased first and then increased with the increase in the IGVF when $N P S H_{\mathrm{a}}$ is large at $1.0 Q_{l d}$, and the pressure pulsation intensity is decreased from 0.062 with the IGVF $=0$ to 0.050 with the IGVF $=2 \%$ first, and then increased to 0.055 with the IGVF $=3 \%$. The pressure pulsation intensity at the model pump outlet is decreased with the increase in the IGVF when $N P S H_{\mathrm{a}}$ is large at $1.25 Q_{l d}$, and the pressure pulsation intensity is decreased from 0.073 with the IGVF $=0$ to 0.046 with the IGVF $=3 \%$. With the increase in the cavitation degree, the pressure pulsation intensity at the model pump outlet is increased with the increase in the IGVF under the above liquid flow conditions.

When cavitation does not occur or the cavitation degree is low, gas has obvious interference on the flow of the liquid under the condition of low liquid flow rates, so the pressure pulsation instability at the model pump outlet is enhanced. With the increase in the liquid flow rate, the interference of gas on the flow of the liquid is weakened and gas can weaken the pressure pulsation of liquid to a certain extent. Therefore, the pressure pulsation intensity at the model pump outlet is decreased to different degrees under the design fluid flow rate and high fluid flow rate conditions. Due to the combined action of the instability of cavitation and gas interference, after the cavitation degree has been increased, the pressure pulsation intensity at the model pump outlet is increased significantly with the increase in the IGVF under the same inlet pressure and different liquid flow rate conditions.

\subsection{Vibration Characteristic}

In order to analyze the characteristic of the vibration intensity of the model pump under different cavitation degrees and IGVF conditions more clearly, the vibration acceleration root-mean-squared value $T$ is introduced, and its definition is shown in Equation (4).

$$
T=\sqrt{\frac{1}{N}} \sum_{k=1}^{N} X_{k}^{2}
$$

where $X_{k}$ is the vibration acceleration at different moments, $\mathrm{mm} / \mathrm{s}^{2}, k=1,2,3,4, \ldots, N$.

The vibration acceleration root-mean-squared value $T$ of the model pump changes with the NPSH $H_{\mathrm{a}}$ of the device under different liquid flow rate and IGVF conditions, as shown in Figures 7-9.

Comparing the maps obtained for the three different mass flow conditions, reported in Figures 7-9, it can be clearly seen that for all the tested values, the vibration intensity changes are small at first, and they increase significantly with the decrease in $N P S H_{\mathrm{a}}$. This is because with the decrease in $\mathrm{NPSH}_{\mathrm{a}}$, the cavitation degree of the model pump increases, generating more bubbles. The influence of bubble collapse on the vibration acceleration of the model pump also increases. 


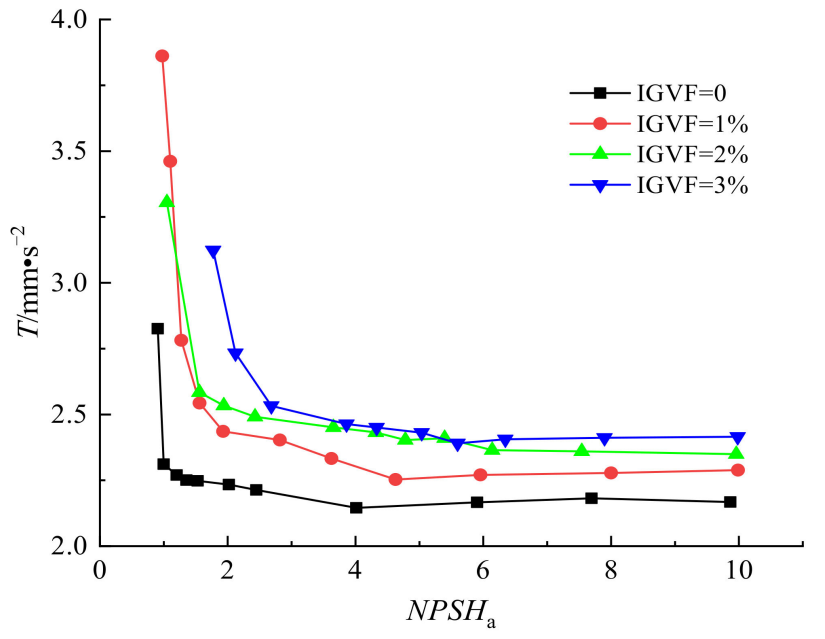

(a)

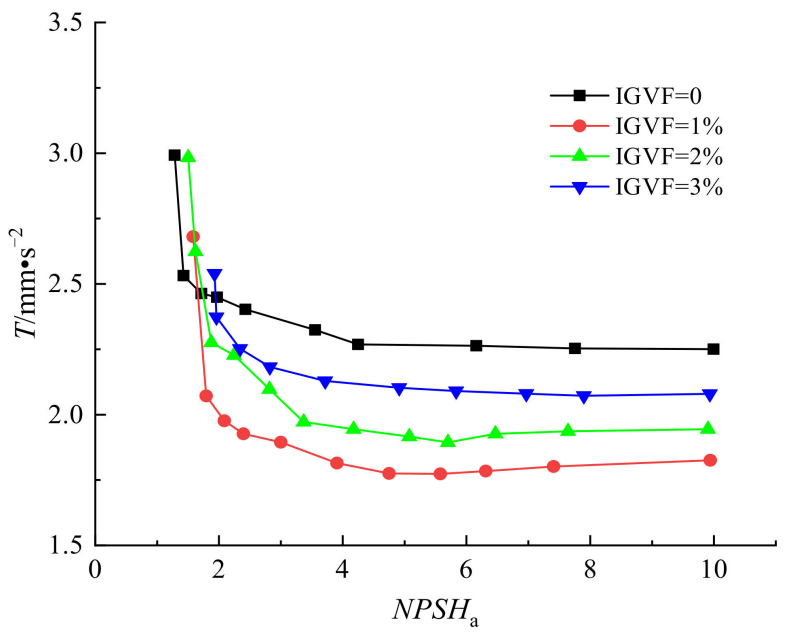

(b)

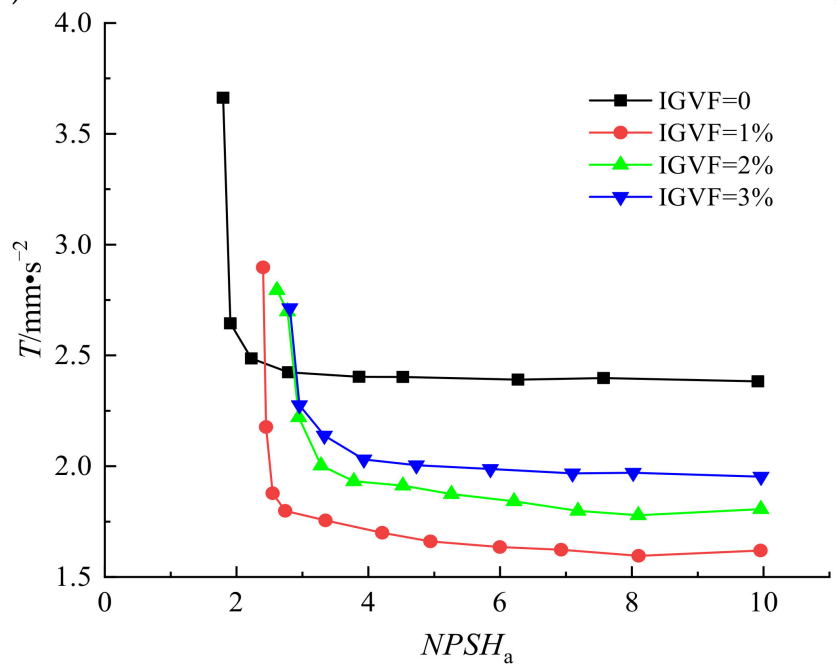

(c)

Figure 7. Vibration intensity of the model pump inlet under different IGVF conditions and different flow rates: (a) $0.75 Q_{l d}$ (b) $1.0 Q_{l d}$ and (c) $1.25 Q_{l d}$.

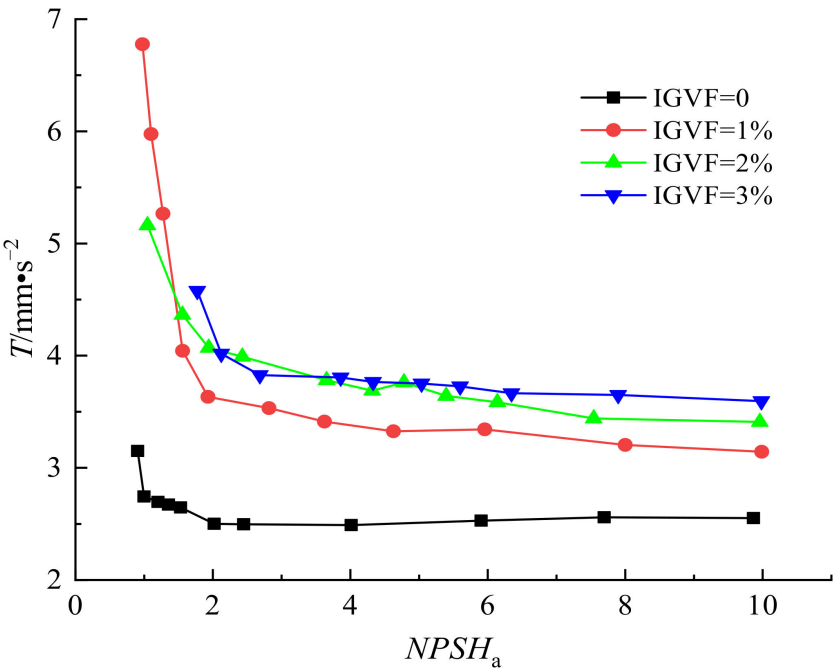

(a)

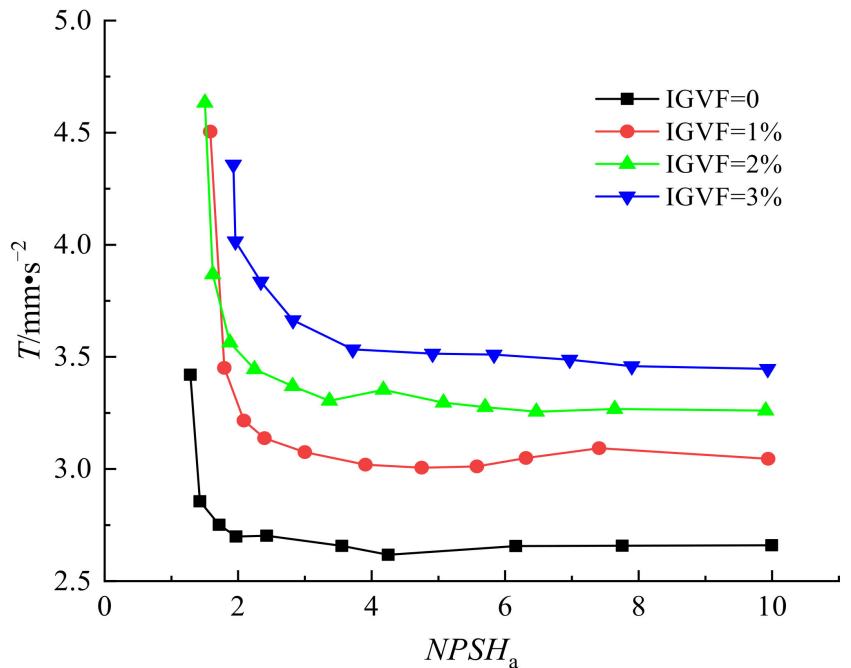

(b)

Figure 8. Cont. 


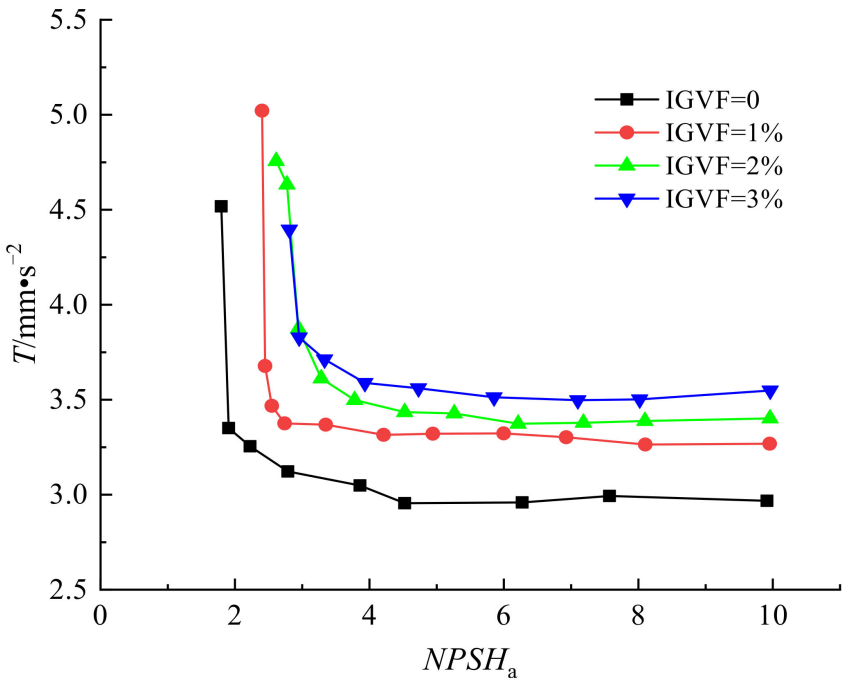

(c)

Figure 8. Vibration intensity of the model pump outlet under different IGVF conditions and different flow rates: (a) $0.75 Q_{l d}$ (b) $1.0 Q_{l d}$ and (c) $1.25 Q_{l d}$.

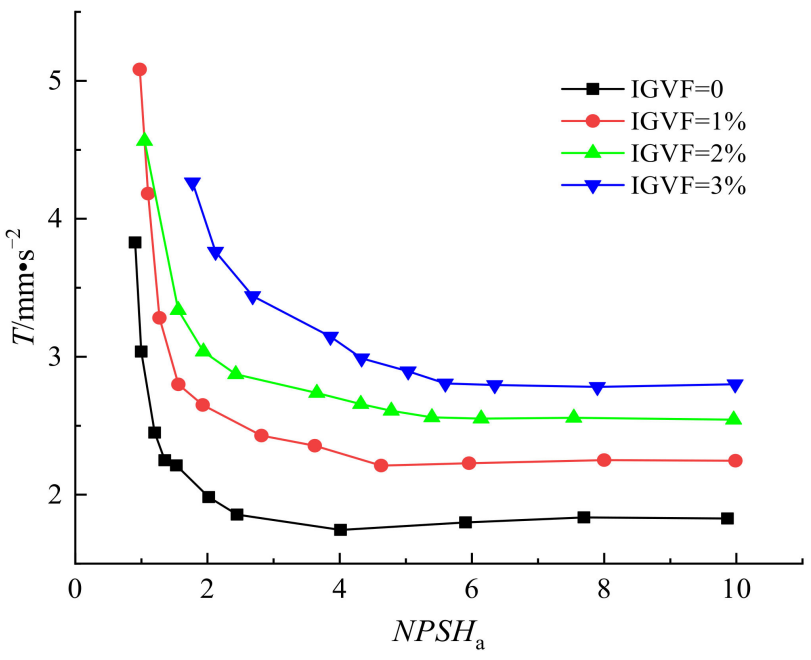

(a)

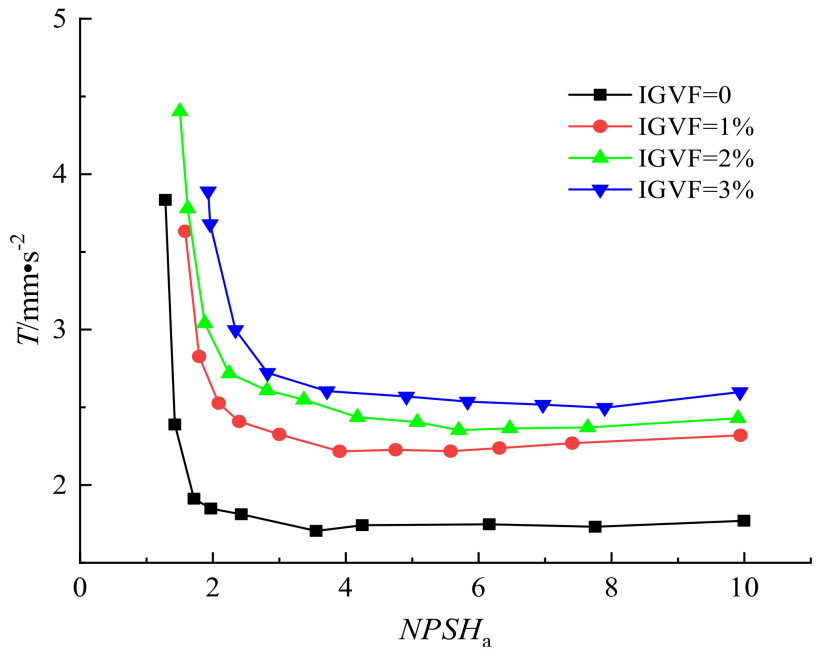

(b)

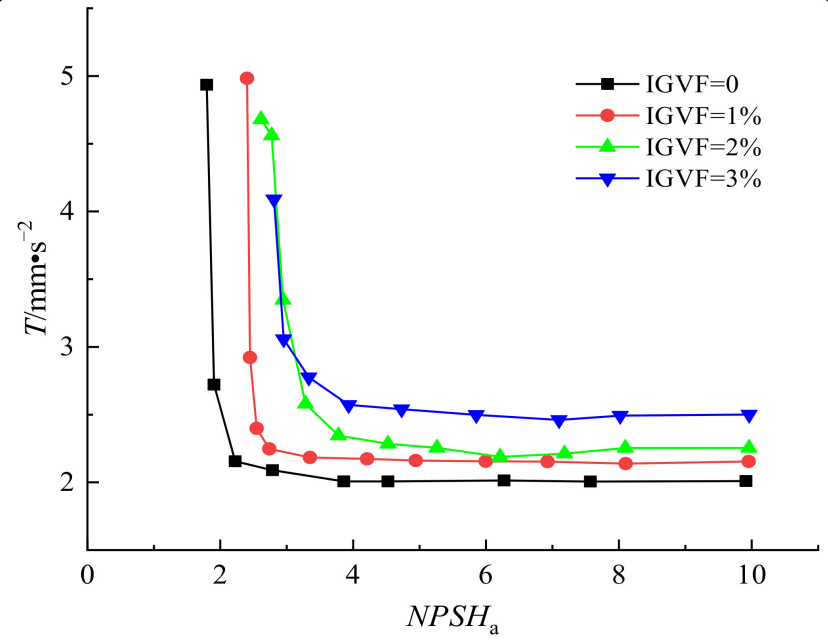

(c)

Figure 9. Vibration intensity of the model pump foot under different IGVF conditions and different flow rates: (a) $0.75 Q_{l d}$ (b) $1.0 Q_{l d}$ and (c) $1.25 Q_{l d}$. 
It can also be seen from Figures 7-9 that vibration intensity at the three measuring points of the model pump is increased slightly with the increase in the IGVF when NPSHa is large at $0.75 Q_{l d}$. The vibration intensity at the pump inlet, pump outlet, and pump foot is increased from $2.37 \mathrm{~mm} / \mathrm{s}^{2}, 2.55 \mathrm{~mm} / \mathrm{s}^{2}$, and $1.83 \mathrm{~mm} / \mathrm{s}^{2}$ with the IGVF = 0 to $2.41 \mathrm{~mm} / \mathrm{s}^{2}, 3.60 \mathrm{~mm} / \mathrm{s}^{2}$, and $2.80 \mathrm{~mm} / \mathrm{s}^{2}$ with the IGVF $=3 \%$, respectively. The vibration intensity at the pump inlet, pump outlet, and pump root is increased with the increase in the IGVF, especially in the pump outlet. This is because with the increase in the IGVF, part of the impeller passage will be blocked and the original stable flow state will be disturbed. Additionally, the vibration acceleration measurement point at the model pump outlet is near the tongue, where the flow is the most chaotic.

It can be seen from Figure 7 that the vibration intensity of the model pump inlet under the condition of $1.0 Q_{l d}$ and $1.25 Q_{l d}$ can obviously be reduced by gas, and the reduction effect is enhanced with the increase in the liquid flow rate. Additionally, the vibration intensity is the minimum at the pump inlet when the IGVF is $1 \%$. Under the condition of $1.0 Q_{l d}$ and $1.25 Q_{l d}$, the vibration intensity at the pump inlet is decreased from $2.25 \mathrm{~mm} / \mathrm{s}^{2}$ and $2.38 \mathrm{~mm} / \mathrm{s}^{2}$ with the IGVF $=0$ to $1.82 \mathrm{~mm} / \mathrm{s}^{2}$ and $1.60 \mathrm{~mm} / \mathrm{s}^{2}$ with the IGVF $=1 \%$, respectively. This is because the pump inlet is far from the rotor part, and the flow is uniform and stable. At the same time, gas is compressible, and a small amount of gas in the incoming flow can weaken the impact of the liquid on the solid wall surface.

The vibration intensity at the three measuring points at different liquid flow rate conditions is increased significantly with the increase in the IGVF after the degree of cavitation is increased, especially in the low liquid flow rate condition. Therefore, it can be inferred that the low liquid flow rate condition is more sensitive to the IGVF.

\section{Conclusions}

The cavitation test rig for pumping gas-liquid two-phase flow was set up in this paper and the cavitation performance of the low-specific-speed centrifugal pump were studied under different liquid flow rates and different IGVF conditions in an experiment. The influence of the IGVF on the head, pressure fluctuation, and vibration characteristics of low-specific-speed centrifugal pump under different degrees of cavitation were analyzed. The main conclusions are as follows:

(1) The performance of the low-specific-speed centrifugal pump can be improved to a certain extent when the IGVF is low, compared with the condition with no gas.

(2) The critical cavitation allowance $N P S H_{\text {cri }}$ is at its minimum when the IGVF is $1 \%$ within a certain liquid flow range. A small amount of gas in the inlet flow can improve the cavitation performance of low-specific-speed centrifugal pumps, and the cavitation performance is improved more obviously under the condition of low liquid flow rates. The $\mathrm{NPSH}_{\text {cri }}$ is decreased from $1.88 \mathrm{~m}$ with the IGVF $=0$ to $1.38 \mathrm{~m}$ with the IGVF $=1 \%$ under $0.75 Q_{l d}$, which is a decrease of $26.6 \%$. The $N P S H_{\text {cri }}$ is decreased from $2.62 \mathrm{~m}$ with the IGVF $=0$ to $2.47 \mathrm{~m}$ with the IGVF $=1 \%$ under $1.25 Q_{l d}$, which is only a decrease of $5.73 \%$.

(3) When cavitation does not occur or the cavitation degree is low, the pressure pulsation intensity at the low-specific-speed centrifugal pump outlet is increased slightly with the increase in the IGVF under low liquid flow rates. The pressure pulsation intensity at the pump outlet is the minimum when the IGVF is $2 \%$ under the fluid design flow rate. Under high fluid flow rates, the pressure pulsation intensity at the pump outlet is decreased with the increase in the IGVF. When the cavitation degree is high, the pressure pulsation intensity at the pump outlet is increased obviously with the increase in the IGVF.

(4) When cavitation does not occur or the cavitation degree is low, gas can reduce the vibration intensity at the low-specific-speed centrifugal pump inlet under the design and high fluid flow rates, and the vibration intensity is the minimum at the pump inlet when the IGVF is $1 \%$. Under the condition of $1.0 Q_{l d}$ and $1.25 Q_{l d}$, the vibration intensity at the pump inlet is decreased from $2.25 \mathrm{~mm} / \mathrm{s}^{2}$ and $2.38 \mathrm{~mm} / \mathrm{s}^{2}$ with the IGVF $=0$ to $1.82 \mathrm{~mm} / \mathrm{s}^{2}$ and $1.60 \mathrm{~mm} / \mathrm{s}^{2}$ with the IGVF $=1 \%$, respectively. The vibration pulsation intensity at the pump foot and the pump outlet is increased with the increase in the IGVF. When the cavitation 
degree is high, the vibration intensity at each measuring point is increased significantly with the increase in the IGVF, especially in the condition of small liquid flow.

Author Contributions: Conceptualization, H.L. and Y.W.; methodology, L.J. and H.L.; software, Y.M.; validation, L.J., R.Z. and J.G.; formal analysis, L.J.; investigation, Y.W.; resources, Y.M.; data curation, L.J.; writing — original draft preparation, L.J.; writing—-review and editing, Y.M.; visualization, L.J.; supervision, H.L. and Y.W.; project administration, H.L.; funding acquisition, H.L. All authors have read and agreed to the published version of the manuscript.

Funding: This research was funded by the National Natural Science Foundation of China, grant number 51979126, 51779106.

Institutional Review Board Statement: Not applicable.

Informed Consent Statement: Not applicable.

Data Availability Statement: The raw data supporting the conclusions of this article will be made available by the authors, without undue reservation.

Acknowledgments: The authors are grateful to the Editor and anonymous reviewers for their constructive comments and suggestions.

Conflicts of Interest: The authors declare no conflict of interest.

\section{References}

1. Brennen, C.E. Cavitation and Bubble Dynamics; Oxford University Press: Oxford, UK, 1995.

2. Li, S.C. Cavitation of Hyfraulic Machinery; Imperial College Press: London, UK, 2000.

3. Yao, Z.; Lu, L.; Gao, Z.; Deng, J.; Wang, F. Experimental investigation of pressure fluctuation and cavitation for a centrifugal pump with different impeller configurations. J. Hydraul. Eng. 2015, 46, 1444-1452.

4. Majidi, K. Numerical study of unsteady flow in a centrifugal pump. J. Turbomach. 2005, 127, 363-371. [CrossRef]

5. Puzik, R.V.; Kovalyov, I.O.; Ratushnyi, O.V.; Dzafarov, T.V.; Petrenko, S.S. The ways to increase the efficiency of the stage of low specific speed. J. Phys. Conf. Ser. 2021, 1741, 012013. [CrossRef]

6. Yuan, J.; Deng, F.; Zhang, K.; Cui, Q.; Si, Q. Status of research on internal flow in blade pumps under gas-liquid two-phase conditions. J. Drain. Irrig. Mach. Eng. 2019, 37, 553-561. (In Chinese)

7. Scott, S.L. Multiphase pumping addresses a wide range of operating problems. Oil Gas J. 2003, 101, 59-71.

8. Shi, G.; Wang, S.; Xiao, Y.; Liu, Z.; Li, H.; Liu, X. Effect of cavitation on energy conversion characteristics of a multiphase pump. Renew. Energy 2021, 177, 1308-1320. [CrossRef]

9. Joe, A. Centrifugal pumps: Avoiding cavitation. World Pumps 2011, 2011, 34-39.

10. Zhao, W.; Zhao, G. An active method to control cavitation in a centrifugal pump by obstacles. Adv. Mech. Eng. 2017, 9, 1687814017732940. [CrossRef]

11. Li, Y.; Feng, G.; Li, X.; Si, Q.; Zhu, Z. An experimental study on the cavitation vibration characteristics of a centrifugal pump at normal flow rate. J. Mech. Sci. Technol. 2018, 32, 4711-4720. [CrossRef]

12. Georgios, M.; Nilla, K.D.; George, A.; Ioannis, A.; Dimitrios, P. Experimental analysis of cavitation in a centrifugal pump using acoustic emission, vibration measurements and flow visualization. Eur. J. Mech. B Fluids 2019, 75, 300-311.

13. Wang, Y.; Liu, H.; Yuan, S.; Wang, J.; Liu, D. Effects of the blade number on cavitation-induced vibration and noise of centrifugal pumps. J. Harbin Eng. Univ. 2012, 33, 1405-1409. (In Chinese)

14. Duplaa, S.; Coutier-Delgosha, O.; Dazin, A.; Roussette, O.; Bois, G.; Caignaert, G. Experimental Study of a Cavitating Centrifugal Pump During Fast Startups. J. Fluids Eng. 2010, 132, 021301. [CrossRef]

15. Coutier-Delgosha, O.; Fortes-Patella, R.; Reboud, J.L.; Hofmann, M.; Stoffel, B. Experimental and numerical studies in a centrifugal pump with two-dimensional curved blades in cavitating condition. J. Fluids Eng. 2003, 125, 970. [CrossRef]

16. Mousmoulis, G.; Kassanos, I.; Aggidis, G.; Anagnostopoulos, I. Numerical simulation of the performance of a centrifugal pump with a semi-open impeller under normal and cavitating conditions. Appl. Math. Model. 2021, 89, 1814-1834. [CrossRef]

17. Wang, Y.; Liu, H.; Liu, D.; Yuan, S.; Wang, J.; Jiang, L. Application of the two-phase three-component computational model to predict cavitating flow in a centrifugal pump and its validation. Comput. Fluids 2016, 131, 142-150. [CrossRef]

18. Wang, J.; Wang, Y.; Liu, H.; Si, Q.; Dular, M. Rotating Corrected-Based Cavitation Model for a Centrifugal Pump. J. Fluids Eng. 2018, 140, 111301.

19. Si, Q.; Cui, Q.; Yuan, S.; Zhang, K.; Cao, R.; Tang, Y. Influence of inlet gas volume fraction on similarity law in centrifugal pumps under gas-liquid two-phase condition. Trans. Chin. Soc. Agric. Mach. 2018, 49, 107-112, 268. (In Chinese)

20. Kim, J.H.; Lee, H.C.; Kim, J.H.; Choi, Y.S.; Yoon, J.Y.; Yoo, I.S.; Choi, W.C. Improvement of hydrodynamic performance of a multiphase pump using design of experiment techniques. J. Fluids Eng. 2015, 137, 081301. [CrossRef]

21. Sato, S.; Furukawa, A. Air-water two-phase flow performances of centrifugal pump with movable bladed impeller and effects of installing diffuser vanes. Int. J. Fluid Mach. Syst. 2010, 3, 245-252. [CrossRef] 
22. Yuan, S.; He, W.; Si, Q.; Yuan, J.; Zhang, H.; Cui, Q. Numerical simulation on gas-liquid two-phase flow in centrifugal pump based on MUSIG model. J. Drain. Irrig. Mach. Eng. 2021, 39, 325-330, 337. (In Chinese)

23. Yuan, J.; Zhang, K.; Si, Q.; Zhou, B.; Tang, Y.; Jin, Z. Numerical investigation of gas-liquid two-phase flow in centrifugal pumps based on inhomogeneous model. Trans. Chin. Soc. Agric. Mach. 2017, 48, 89-95. (In Chinese)

24. Neumann, M.; Schäfer, T.; Bieberle, A.; Hampel, U. An experimental study on the gas entrainment in horizontally and vertically installed centrifugal pumps. J. Fluids Eng. 2016, 138, 091301. [CrossRef]

25. Shao, C.; Li, C.; Zhou, J. Experimental investigation of flow patterns and external performance of a centrifugal pump that transports gas-liquid two-phase mixtures. Int. J. Heat Fluid Flow 2018, 71, 460-469. [CrossRef]

26. Ge, Z.; He, D.; Huang, R.; Zuo, J.; Luo, X. Application of CFD-PBM coupling model for analysis of gas-liquid distribution characteristics in centrifugal pump. J. Pet. Sci. Eng. 2020, 194, 107518. [CrossRef]

27. Si, Q.; Cui, Q.; Zhang, K.; Yuan, J.; Bois, G. Investigation on centrifugal pump performance degradation under air-water inlet two-phase flow conditions. La Houille Blanche 2018, 3, 41-48. [CrossRef] 